\title{
Some reflections on clinical teaching
}

\author{
Narada Warnasuriya ${ }^{1}$ \\ Sri Lanka Journal of Child Health, 2000; 29: 3-10
}

(Key words: clinical teaching)

The three primary roles of a physician are service, teaching and research. The relative importance one attaches to each of these roles would depend on one's own personal interest, orientation and the context in which one works. Whatever the context, that one has a role to teach is indisputable. In fact the word doctor is derived from the Latin word 'docere', to teach.

Hippocrates, the ancient Greek physician by whose oath we are still guided, with some modification, clearly identified a doctors obligation to teach.

"I swear by Apollo the physician that by precept, lecture and every other mode of instruction, I will impart a knowledge of the art to my own sons and those of my teachers and to disciples bound by a stipulation and oath according to the law of medicine".

Though medical teaching by apprenticeship was traditionally practised from ancient times, clinical teaching as we know today i.e. by the bedside of a patient in a public hospital, was first championed by Franciscus De Leboe Sylvius, who is remembered today chiefly for the brain structures he described, aqueduct of Sylvius and the Sylvian fissure. Sylvius was famous as a medical practitioner and after his appointment to the chair of medicine at Leiden he became the most famous clinical teacher of the $17^{\text {th }}$ century. In 1964 Sylvius wrote "My method hitherto unknown here, and possibly anywhere else, is to lead my students by the hand to the practice of medicine, taking them every day to see patients in the public hospital, that they may hear patient's symptoms and see their physical findings. Then I question the students as to what they have noted in the patients and about their thoughts and perceptions regarding the causes of the illness and the principles of treatment".

Professor of Paediatrics, University of Sri Jayawardenepura.

*Address given on induction as President SLCP October 1999.

This is not an inappropriate description of what is expected of a good clinical teacher even today. Another strong advocate of bedside clinical teaching was William Osler, a Canadian physician who held the posts of Professor of Medicine in three countries, Mcgill in Canada, Johns Hopkins in the United States and at the turn of the century at Oxford in England. At the time Osler came into prominence western medicine was strongly under the influence of the German scientific tradition and was being taught mainly in lecture rooms and laboratories. Osler led the movement to take it back to the bedside.

He was a man of remarkable wit and intellect who left an indelible mark on the methods of modern clinical teaching. He described bedside teaching as the most useful and important work he had been called upon to do. Osler took as his motto the maxim that the "whole art of medicine is in observation". He said that there should be "no teaching without a patient for a text and the best teaching is that taught by the patient himself."

Osler's methods were described by his student Henry Christian: "He would go to a patient's bed, stand near the head of the bed at the patient's right side, give him a cheery greeting, and if he was a new patient ask for his history which would then be given by the student clinical clerk. After it had been commented on, possibly criticised and often added to by Dr. Osler, the report of the physical examination was called for..... Usually Dr. Osler made some examination himself and demonstrated and discussed the salient features, all the time mingling his discussion with remarks and explanation to the patient so that he would not be mystified or frightened".

Thus, our educational tradition stems from bedside teaching. Unfortunately due to a multiplicity of reasons there has been a tendency to move away from the bedside into a classroom or to a hospital corridor. Some of the reasons identified for this shift are discussed here. 


\section{Concern for patient's well being and privacy}

There is a feeling that discussing the case history in front of the patient is troublesome to the patient and a threat to his privacy. But the evidence for this is scanty. The few studies on the effect of bedside teaching on patients indicate that for the most part patients appreciate the obvious attention being devoted to them. These studies confirm that ward round teaching when conducted tactfully and sympathetically is not a traumatic emotional experience to patients. They help to educate and reassure them.

\section{Passive view of education}

Some teachers view teaching as a mere transfer of knowledge from teacher to student. They tend to convert the ward round to a series of mini lectures on topics that happen to arise. Such teachers would prefer a class room.

\section{Insecurity of teacher}

Some feel uncomfortable when they are presented with the reality of a patient and his problem and are unable to analyse and discuss it adequately. In a more formal setting they feel comfortable and would discuss topics which they feel expert in.

\section{Over abundance of data}

The amount of information, especially laboratory derived data that may be available, is sometimes overwhelming. There may be pressure from the students and residents to discuss some of the theoretical aspects of their interpretation. Although occasionally justifiable, this sort of exercise reduces the student's opportunity to gain directly from the patient.

\section{Lack of interactive skills}

Some teachers clearly lack the ability to interact with the students and the patients without causing discomfort to either. Bedside teaching should be an opportunity to observe an experienced clinician in action, especially in his interpersonal and communication skills. Clinicians who lack these skills tend to avoid the bedside.

\section{Lack of space}

This is probably one of most important practical reasons for the shift, in the overcrowded teaching hospitals in our part of the world. The side rooms built for teaching with the best of motives may further aggravate the position. It tempts one to take a mere glance at the patient and then indulge in a mostly theoretical discussion based on a summary of a student history in the comfort of a chair in a side room. Even if you move from the bedside to the side room the patient should be close to you when you are teaching.

The advantages of bedside teaching are many. Some are discussed here ${ }^{1}$.

\section{The patient is seen as an individual}

After all it is as important to know what sort of person has the disease as to know what sort of disease the person has.

During bedside teaching both students and patients see patient care as a collaboration between patients, doctors and other health professionals like nurses.

\section{Teaching role of the doctor}

The physician's role in advising and instructing the patient, becomes clearly visible to the student during bedside teaching.

\section{Contact with the patient is prolonged}

During bedside teaching the clinician is not dependent on a summary of the history recited by an intern. There is time for an unhurried and unprejudiced view of the patient. Unanticipated, sometimes serendipitous observations are made on the basis of a student history and examination. When this happens a simple case history becomes more exciting and the patient benefits in the end.

\section{Human dimension can be incorporated into the clinical learning process}

The good bedside teaching rounds cease to have a narrow medical focus. Psychological and social aspects of the illness are touched on. The physical presence of the patient demands that he be regarded as a subject rather than an object and this facilitates the goal of humanising medical care.

"Criticism of modern medicine has been mirrored by increasing disenchantment with modern medical practice on the part of the public, media, politicians and some doctors themselves". It is not the editor of the Ceylon Daily News I am quoting but David Weatherall, the Editor of the Oxford Text Book of Medicine. To continue, "Modern medical science 
with it's increasingly reductionist approach to the study of disease has tended to focus more on the disease mechanisms than on those suffering from the diseases. We must redress this balance and return to a more holistic approach to medical care". It is in this context that a return to the bedside will provide a valuable opportunity to encourage and exemplify attitudes and values of enduring worth to the student and the patient.

In view of these unique features, there is no doubt that the patients' bedside should continue to be the chief arena of medical education, at least for the foreseeable future. However, this is not to deny the need for other complementary settings for clinical teaching. The General Medical Council defined the primary aim of undergraduate medical education in terms of acquiring "an understanding of health and disease and the prevention and management of the latter in the context of the whole individual in his or her place in the family and society."

The Edinburgh declaration on medical education adopted in 1993 proclaims $^{2}$,

"Good medical education demands a useful match with the health care system. A contemporary doctor cannot be trained in a teaching hospital alone". The need for more real world settings for clinical teaching is thus evident.

There is at present a considerable disjunction between medical education and medical practice. Though the majority of clinicians spend most of their professional life in ambulatory practice only a small part of clinical teaching at present is done in this context. This is partly due to logistic constraints. Greater utilisation of hospital clinics, family practices and field placements in the community will enable the students to see a more realistic array of health problems, human conditions and professional role models which can enlarge and enrich their hospital experiences.

Community based teaching enables the students to see patients in their own environment and to achieve a clear understanding of how illness affects all aspects of a person's life. They also see how health services are provided, the importance of the team approach and how primary and secondary services interact.

One of the earliest community based learning experiences introduced into the medical curriculum in Sri Lanka was the social paediatrics programme which was initiated by Prof. Priyani Soysa and Prof.
Earl De Fonseka in 1967. 1 was fortunate to be in the first group of students who participated in this programme. I still remember vividly the details of the family we were assigned, that of a driver in the CTB (Ceylon Transport Board) living down Rampart road in Etul Kotte. It was an academic activity which left a lasting impression on me. Subsequently, having joined the academic Department of Paediatrics in Colombo, under the guidance of Prof. Soysa, I was involved in nurturing and further developing this programme and incorporating it into the scheme of continuous assessment when paediatrics became a separate subject. As far as I am aware almost all the departments of paediatrics in Sri Lanka have a similar programme as a part of their curriculum today. At USJP (University of Sri Jayawardenepura) we have a family attachment programme in conjunction with the Department of Community Medicine \& Family Medicine and the Department of Psychiatry.

There is no doubt that it provides the students with insights into child care, and family health which they would not have gained in a purely hospital based clinical clerkship.

This is a list of some topics that came up for discussion at the family attachment programme during one academic year.

\section{ASPECTS OF CHILD CARE LEARNT IN FAMILY ATTACHMENT}

Adoption
Well baby care
Lactation management
Formula feeding
Probation
Alcoholic father
Wife battering
Child abuse
Single parent
Drug addict parent
Mother in the Middle East
Death of a parent
School enrolment
School failure
Preschool

One major drawback in the hospital oriented traditional clinical course which is on the lines of an apprenticeship is the haphazard nature of the exposure to clinical problems. Students are allocated to clinical firms and see the patients that are admitted to the ward. Little overall planning can be done as it is impossible to predict which patients would be 
available at a given time. The assumption is that over several such attachments the students would be exposed to an acceptable range of conditions.

Most medical schools which are faced with this problem have developed a strategy of providing the students with a list of core conditions they are supposed to see. These are some guidelines for deciding on what a core topic is, prepared by a group of paediatric educators ${ }^{3}$.

\section{What is core?}

A topic should be regarded as core if

- It is common.

- It has a serious impact on the health of children and is preventable by early recognition and management.

- It has a screening programme, vaccine or other public health measure in operation.

- It serves as a study model of an important concept.

- It has a local flavour.

- It is likely to be important in the future.

As a new medical school, functioning with a newly commissioned clinical unit, we at Jayawardenepura were concerned about this possible deficiency. We took early steps to rectify it. After discussion with our colleagues in CSTH (Colombo South Teaching Hospital) and SJGH (Sri Jayawardenepura General Hospital), we provided a list of 20 core conditions, which the students had to see in their $3^{\text {rd }}$ and $4^{\text {th }}$ year clinical clerkships and expanded this list in the final year clerkship in the university unit.

Common clinical presentations in the paediatric ward to be seen in the $3^{\text {rd }} \& 4^{\text {th }}$ year clinical clerkship

1. Acutely febrile child

2. Child with fever, cold, cough and dyspnoea

3. Child with recurrent wheeze

4. Child with acute diarrhoea

5. Child with acute abdominal pain

6. Child with vomiting

7. Child with a bleeding tendency

8. Child with a limp/arthritis

9. Child with oedema
10. Child with fever and convulsions

11. Child with failure to thrive

12. Child with developmental delay

13. Child with persistent cough

14. Child with progressive pallor

15. Child with heart failure

16. Child with hepatosplenomegaly

17. Child with recurrent convulsions

18. Child with skin rash

19. Child with lymphadenopathy

20. Newborn with jaundice

We also employed several strategies to bridge any deficit. These included problem oriented tutorials to small groups using real life clinical problems, clinical lecture demonstrations to ensure that the whole batch saw the interesting patients admitted and carefully planned sessions of slide teaching to see physical sign which they may not have seen in the ward. The family attachment was used to great effect in seeing problems not usually admitted to the wards.

We have now completed a self audit of our performance with the first batch of students in respect of 40 core conditions that were identified. The list of 40 was as follows.

List of core conditions in paediatrics (to be seen by the end of the course)

1. Normal newborn

2. Birth asphyxia

3. Low birth weight

4. Neonatal sepsis

5. Neonatal jaundice

6. Congenital malformation

7. Genetic disorder

8. Development delay

9. Behaviour disorder

10. Epilepsy

11. Febrile convulsion

12. Meningitis/Encephalitis

13. Failure to thrive

14. Short stature

15. Nutritional disorder

16. Poisoning

17. Child abuse

18. URTI (Upper respiratory infection)

19. LRTI (Lower respiratory infection)

20. Bronchial asthma

21. Infective gastroenteritis

22. Intestinal parasites

23. Infective hepatitis

24. Abdominal pain/vomiting

25. Viral fever

26. DHF (Dengue haemorraghic fever) 
27. PUO (Pyrexia of unknown origin)

28. TB (Tuberculosis)

29. AGN/Nephrotic syndrome

30. Childhood malignancy

31. UTI (Urinary tract infection)

32. JCA (Juvenile chronic arthritis)

33. Child with a limp

34. Rheumatic fever

35. CHD (Congenital heart disease)

36. Haemolytic anaemia

37. Bleeding diathesis

38. Atopic diathesis

39. Skin infections

40. Endocrine disorder

As you would see, the list contains some traditional diagnoses as well as clinical problems, a mixture of the ICD (international classification of deaths \& disease conditions) and ICHPPC (international classification of health problems in primary care).

These are the results of our audit. They are applicable only to final year teaching.

\section{To what extent was the core seen / taught?}

10/40 (25\%) Clerked by an individual student

30/40 (75\%) Covered during Ward/Clinic teaching with each group of students

12/40 (30\%) Discussed in Family Attachment Programme with each group of students

22/40 (55\%) Covered in tutorial for all

29/40 (73\%) Taught in Lectures for all

21/40 (53\%) Shown in Clinical lecture demonstration for all

35/40 (83\%) Shown in Slide teaching for all

I present them without comment as I have no comparable data at present from the other established units. The majority of these students are now doing their internship in clinical units across Sri Lanka. We will be appreciative of any feed back, positive or negative about their performance.

Partly as a response to the problem of haphazard clinical exposure and partly with the progress in educational technology, many alternative approaches to traditional ward teaching have been developed. These include simulation and role play, skills laboratories particularly for acquisition of procedural skills and computer assisted learning packages. However these approaches can only be complementary to traditional clinical teaching. They are not a substitute for such teaching and will never be. As Freud said "We must not give a starving man a menu and pretend that it is a meal"

Having dealt so far with the history of clinical teaching, its underlying ethos, and the need for varied settings in which to do it, I would like to move on to another aspect viz. what an effective clinical teacher needs to know in order to teach well. The tradition that teaching is part of being a doctor assumes that everyone can and should teach. Conventional wisdom suggests that knowledge of medicine is all that is necessary to be a good clinical teacher. "if you understand your discipline then you should be able to teach it". This is the assumption. This assumption is also extended to practical skills where the often cited dictum is "See one, do one and teach one"

But both observational studies and student perceptions of clinical teaching do not confirm this to be adequate. In fact we can no longer assume that because some can do the job that he can also teach the skill. The task faced by the clinical teacher is unique in the entire realm of teaching. In no other field does the context demand of the teacher this degree of preparedness without preparation.

In spite of there being a great need only a few pertinent studies have been conducted on clinical teaching. Though these studies have been done in the west, the universal nature of clinical teaching process suggests cross cultural applicability of the conclusions.

In order to identify the components of knowledge that effective clinical teachers of medicine need, Irby carried out a descriptive study of six distinguished clinical teachers at the Washington School of Medicine $^{4}$. He used a case study design relying on data from interviews, a structured task and observations of ward teaching. He identified six domains of knowledge which are essential to teaching excellence in the context of teaching rounds. The six domains of knowledge are depicted diagrammatically 


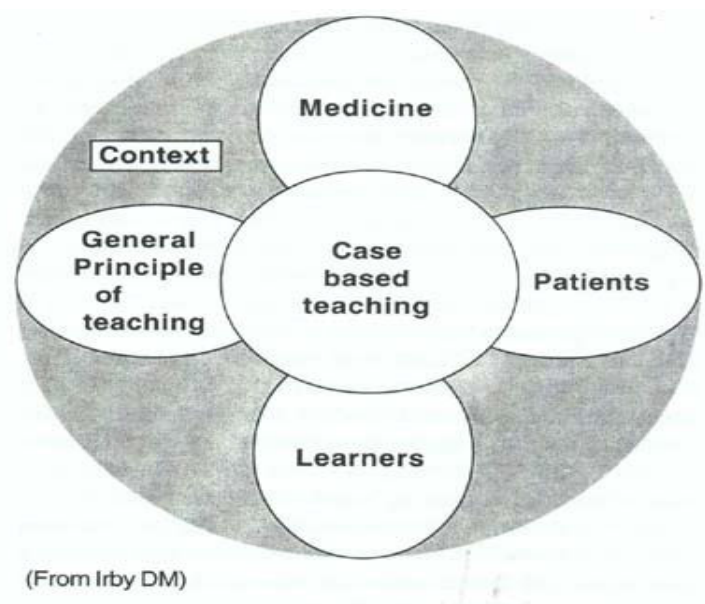

In the background is the context. Knowledge of the context of the medical practice including geographical, socio-cultural and historical background is an important item. Taking the petals one by one, the first is knowledge of medicine. This includes general medical knowledge including basic sciences and epidemiology. Next is knowledge of patients. This includes personal knowledge of the medical aspects of the patients being discussed. Next is knowledge of the learners. This includes knowledge of their level of training, their weaknesses and strengths. Next is knowledge of general principles of teaching, such as need for active involvement, need to connect the case to broader concepts, need to be practical and relevant.

Finally in the centre are case based teaching scripts. This needs further explanation. This is also called content specific instruction. It is a special form of knowledge unique to teachers which develops through the repetitive experience of teaching specific content to specific students. The resulting knowledge becomes organised in one's mind as a teaching script. The teaching scripts are similar to play scripts or screen scripts that dictate action on the stage. They contain main goals of instruction, key teaching points, specific examples/anecdotes, common misconceptions of learners, procedures to circumvent the learning difficulties etc. It is a synthesis of all items of knowledge shown in the periphery of the figure that enables the teacher to develop the case based teaching script shown in the centre. This special form of knowledge is what separates good teachers from mere content experts.

There is another crucial aspect which needs to be achieved in good clinical teaching. That is to enable the student to appreciate the diagnostic process and to apply it in a clinical context. The effectiveness of a clinician depends on two main characteristics viz. his skill in eliciting information from the patient by interview, observation and physical examination and his ability to interpret such clinical information in the frame work of a body of basic knowledge. Studies of the clinical diagnostic process show that physicians form diagnostic hypotheses on the basis of minimal clinical findings and that the hypotheses create a context in which to gather additional relevant data. Thus, by a repetitive process, the hypotheses are either eliminated or confirmed and those that survive are made progressively more specific. Though this is what is practised, this is not what is taught. Instead, students are expected to learn diagnostic problem solving by reading text books, listening to case presentations and observing physicians at work. They have to re-discover the process of clinical reasoning by trial and error. It is time that we preach what we, the teachers, practice and teach clinical diagnosis using the hypothetico deductive method ${ }^{5}$.

The attributes of an effective clinical teacher have been identified on the basis of opinion of experts, perception of students and from observation of actual clinical teaching. Considering the limited nature of the research there is a remarkable consistency in the results. Newbie and Canon in their outstanding handbook for clinical teachers have posed these attributes in the form of ten questions which you could ask your-self ${ }^{6}$.

1. Do you encourage active participation by the students and avoid having them stand around in an observational capacity?

2. Do you have and demonstrate a positive attitude to your teaching?

3. Is the emphasis of your teaching on applied problem solving?

4. Do you focus on the integration of clinical medicine with the basic and clinical sciences or do you spend most of the time on didactic teaching of factual material?

5. Do you closely supervise the students as they interview and examine patients at the bedside and provide effective feedback on their performance or do you rely on their verbal case presentations in the teaching room?

6. Do you provide adequate opportunities for your students to practice their skills? 
7. Do you provide a good role model, particularly in the area of interpersonal relationships with your patients?

8. Does your teaching provide stimulation and challenge?

9. Is your teaching generally patient oriented or does it tend to be disease oriented?

10. Are you friendly, helpful and available to your students?

Should your honest answer to most of those questions be 'no' then you are probably a typical clinical teacher as many studies have shown that these attributes are rarely present. Just becoming aware of these attributes should encourage you to be more self critical of your approach in the future. If your honest answer to most of those questions is 'yes' then you are truly an excellent clinical teacher.

To summarise the main attributes of a good clinical teacher I have selected a study done at the Hospital of Sick Children in Toronto by Hilliard ${ }^{7}$. The faculty and residents in the paediatric training programme identified the following characteristics out of a possible forty as those being descriptive of the most outstanding clinical teacher in their opinion.

1. Teaches approaches to problems, basic concepts, and not simply facts.

2. Able to communicate ideas and knowledge clearly and presents discussions in a clear, lucid, and organised fashion.

3. Excellent clinician in dealing with medical problems in thorough, complete organised approach.

4. Able to stimulate intellectual curiosity and promote self-directed learning.

5. Enthusiastic about teaching and seems to enjoy interaction with students and residents.

6. An excellent role model in the way he or she deals with patients and families.

So far, what I have attempted to do is to create a profile of a good clinical teacher in your mind. However I would not like to leave you with the impression that there is a stereotype of a good clinical teacher. Observational studies confirm that no two clinicians approach their teaching responsibility in exactly the same manner. During years of experience each develops a particular instructional style. The variety of styles that can effect good clinical teaching has led some to believe that excellent teaching, like good tea, can be appreciated but not analysed and documented. What is necessary is to find an approach to teaching that fits your own personality.

After all, education is about students who learn and not about professors who perform. That is not to deny that students who learn are the finest fruits of the teachers who teach.

Students learn in diverse ways including those that bypass the teachers entirely. However whether it be in the lecture room, the field or ward, the teacher has the power to create the conditions that can help students to learn. They can help them to learn a great deal, or prevent them from learning anything at all. For example, teachers who talk but do not listen may produce students who listen but do not talk. A further word of caution is necessary. Good teaching has to be in concert with learning. If not, what teachers teach and what students learn may not be the same. We may think that we have taught some fundamental concept. But what they have learnt may be quite different from what we taught. I am sure all teachers have encountered this exasperating fact, at some time or the other.

Medical educationists are well aware of the three curricula model of a medical course ${ }^{8}$. The planned, taught and learnt curricula. Although there is overlap between the three they are not the same.

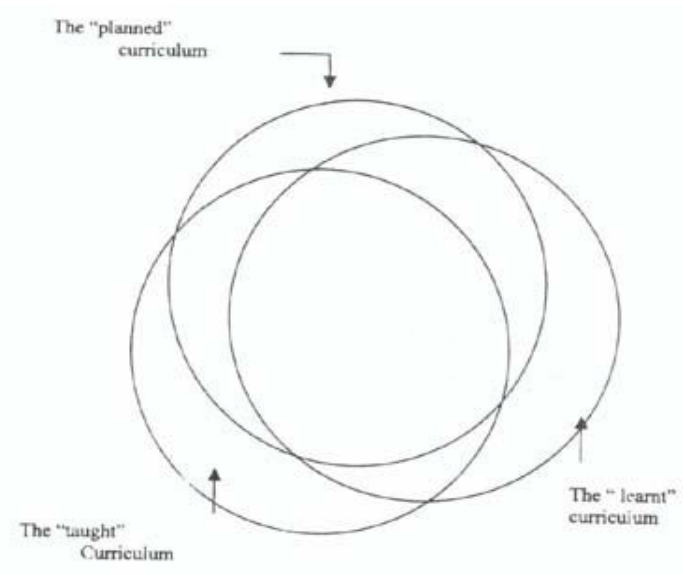

Three curricula model of any medical course (From Lowry S) 
This brings me at last to a very important aspect of clinical teaching viz. It's potential to influence the attitudes of the learners.

Kimball, writing on medical education, hypothesised that the process of medical education has the potential for providing greater growth and development, and hence humanisation of the individual than any other experience afforded to mankind ${ }^{9}$. Although there is an element of hyperbole, the statement is not without substance. However it is in this realm that the individuality of the teacher really matters.

Parker J. Palmer, a well known American teacher of teachers in his book entitled "Courage to Teach" puts forward one simple premise. "Good teaching cannot be reduced to technique. Good teaching comes from the identity and integrity of the teacher". To quote him further "good teachers are truly present in their classroom deeply engaged with the students and their subjects. They are able to weave a complex web of connections between themselves their subjects and their students. The connections made by good teachers are not in their methods, but in their hearts, heart in the ancient sense of the word, the place where intellect, emotion, spirit and will converge in the human self" ${ }^{10}$.

The eloquent imagery of Palmer's words will strike a chord in the heart of any teacher with a passion for teaching. Such teachers will bring out the best in their students. Such teachers will enable students to develop an attitude to learning that is based on curiosity and exploration of knowledge. Such teachers will enable their students, in the words of William Blake,

"To see a world in a grain of sand

And a heaven in a wild flower Hold infinity in the palm of hour hand An eternity in an hour."

\section{References}

1. Linford E W, Neelon F A. The case for bedside rounds. New England Joumal of Medicine 1980; 303 (21):1230-3.

2. Walton H J. Proceedings of the world summit on medical education. Medical Education 1993; 28 supplement 1: 140-9.

3. Hadded D, Robertson K J, Cockburn F, Helms P, McIntosh $\mathrm{N}$ and Olver R E. What is core? Guidelines for the core-curriculum in Paediatrics. Medical Education 1997; 31: 354-8.

4. Irby D M. What clinical teachers in medicine need to know. Academic Medicine 1990; 69(5): 333-42.

5. Kassirer J R. Teaching clinical medicine by iterative hypothesis testing. New England Joumal of Medicine 1983; 309(15):921-3.

6. Newble D, Cannon R. A handbook for clinical teachers. Boston;MTP press, 1983.

7. Hilliard RI. The good \& effective teacher as perceived by paediatric residents \& faculty. American Journal of Diseases of Children 1990; 144:1106- 10.

8. Lowry S. Curriculum Design. British MedicaI Journal 1992; 305:1409-11.

9. Kimball C P. Medical Education as a humanising process. Journal of Medical Education 1973; 48:71.

10. Palmer $\mathrm{P} J$. The Courage to Teach. San Francisco; Jossey-Bass Publishers, 1998. 
